\title{
Analisis kajian fisiologi tumbuhan budidaya buah naga (Hylocereus spp.) menggunakan lampu di Banyuwangi
}

\author{
Heni Setyawati \\ Prodi Tadris Biologi, Fakultas Tarbiyah dan Ilmu Keguruan, \\ Institut Agama Islam Negeri Jember, Jember 68136 \\ henisetyawati0787@gmail.com
}

\begin{abstract}
Abstrak
Kajian ini bertujuan untuk mengetahui dan mendeskripsikan kajian fisiologi tumbuhan tentang budidaya buah naga (Hylocereus spp.) menggunakan lampu pada malam hari di Banyuwangi, Jawa Timur. Metode yang digunakan metode pengumpulan data dan studi pustaka. Tanaman buah naga sebagai tanaman LDP jika mendapat lama penyinaran yang lebih panjang, akan memacu pembungaan. Tanaman buah naga termasuk tanaman jenis CAM (crassulacean acid metabolism). Pada malam hari stomata tumbuhan CAM terbuka di malam hari dan akan tertutup di siang hari. Pemberian penerangan menggunakan bola lampu pada malam hari menyebabkan pembukaan stomata semakin optimal. Dengan demikian laju pengambilan $\mathrm{CO} 2$ sebagai sumber fotosintesis juga meningkat. Penambahan penyinaran dapat berfungsi sebagai penambahan periode fotosintesis, dengan demikian asimilat yang dihasilkan akan meningkat. Akumulasi asimilat yang memadai akan memungkinkan terjadinya inisiasi primordia bunga pada bagian meristem.
\end{abstract}

Kata kunci: fisiologi tumbuhan, buah naga, lampu

\section{Abstract}

The aims of this study are to determine and describe the study of plant physiology about the cultivation of dragon fruit (Hylocereus undatus Haw.) using lights at night in Banyuwangi, East Java. The method of this study are data collection and literature study. Dragon fruit as Long Day Plants will stimulate flowering if thei get longer exposure time. Dragon fruit plant linclude CAM (crassulacean acid metabolism). The CAM plant's stomata are open at night and will be closed during the day. Giving light bulb treatment at night maximizes the stomata opening. Thus the rate of $\mathrm{CO} 2$ taking as the raw material of photosynthesis will increase. The addition of lighting can serve as an additional period of photosynthesis. So that the assimilate will increase. The adequacy of assimilate will allow the initiation of flower primordia at the meristem.

Keywords: plant physiology, dragon fruit, lighting

\section{PENDAHULUAN}

Banyuwangi merupakan salah satu kabupaten di Jawa Timur yang merupakan penghasil buah naga. Perkembangan buah naga di Banyuwangi semakin meningkat pesat. Hasil wawancara dengan petani buah naga di Banyuwangi menyatakan bahwa para petani buah naga terus berusaha untuk meningkatkan hasil produksi buah naga dengan beragam cara antara lain yaitu dengan aplikasi gibro (hormon giberelin) dan memberikan penyinaran 
menggunakan bola lampu di setiap tanaman buah naga pada alam hari. Menurut Firdaus, dkk (2019) mudahnya budidaya menanam buah naga, membuat daya tarik warga Banyuwangi khususnya di wilayah Banyuwangi selatan menjadi petani buah naga dadakan. Dinas Pertanian Kabupaten Banyuwangi tahun 2017 mencatat luas lahan pertanian buah naga mencapai $2.800 \mathrm{Ha}$. Meskipun demikian 90\% dari luas lahan, budidaya buah naga tersebut masih dilakukan secara tradisional dengan menggantungkan pada siklus panen. Tahun 20172018 secara drastis banyak petani buah naga mulai memanfaatkan penyinaran bohlam lampu untuk membantu meningkatkan kapasitas produksinya tanpa harus memperluas lahan. Menurut Dadang 2018) fenomena pemberian penyinaran lampu di kebun buah naga yang dilakukan oleh para petani Banyuwangi sangat masif. Perlakuan penyinaran lampu dapat menumbuhkan calon buah serta dapat membuat berbuah saat tanaman buah naga masuk masa istirahat buah (off-season). Pada saat ini diasumsikan ketersediaan buah naga terbatas sehingga harga buah naga naik. Pada akhirnya dapat meningkatkan pendapatan petani.

Menurut (Jiang et al., 2012), buah naga merupakan buah musiman. Untuk wilayah Indonesia buah naga hanya berbunga pada bulan Oktober-Maret. Selain waktu tersebut buah naga tidak berbunga, masa ini disebut sebagai masa off-season. Menurut Elok dkk., 2016) masa off-season menjadi peluang besar bagi petani buah naga untuk meningkatkan pendapatan. Hal ini dissebabkan oleh harga jual buah naga pada masa off-season relatif lebih mahal hingga 2-3 kali lipat dari harga normal pada musimnya dan permintaan terhadap buah naga meningkat. Salah satu perlakuan yang diberikan petani di wilayah Banyuwangi terhadap buah naga pada masa off-season adalah dengan memberikan pencahayaan di malam hari (18.00-06.00 WIB). Perlakuan pemberian pencahayaan terhadap buah naga telah terbukti dapat merangsang buah naga untuk berbunga meskipun pada masa off-season (Reindeers, 2010). Menurut (Tran et al., 2015) hasil penelitian menunjukkan bahwa setelah 33-48 hari pencahayaan dan mulai berbuah setelah 46-59 hari pencahayaan, buah naga dapat berbunga.

Kajian ini bertujuan untuk mengetahui mengetahui dan mendeskripsikan kajian fisiologi tumbuhan tentang budidaya buah naga (Hylocereus undatus Haw.) menggunakan lampu pada malam hari di Banyuwangi, Jawa Timur. Metode yang digunakan adalah wawancara dan studi pustaka.

\section{PEMBAHASAN}

Berdasarkan hasil wawancara dengan beberapa petani buah naga di Banyuwangi menyatakan bahwa alasan mereka tertarik untuk menanam buah naga adalah karena budidaya buah naga mudah dilakukan, mudah perawatannya, serta tidak memerlukan pupuk yang 
banyak seperti tanaman budidaya lainnya. Petani Banyuwangi memberikan perlakuan penyinaran menggunakan lampu bohlam ketika hari mulai gelap dengan alasan untuk meningkatkan hasil dan agar tanaman dapat berbuah ketika tidak pada musim berbuah. Hasil wawancara ini sesuai dengan hasil penelitian Palupi dan Farida tahun 2013 yang menunjukkan bahwa penambahan penyinaran dengan menggunakan lampu 45 dan 55 watt dapat menginduksi pembungaan buah naga di luar musim. Kuncup bunga pertama muncul pada 54 dan 42 hari setelah penambahan penyinaran masing-masing dari penambahan penyinaran 45 dan 55 watt. Perkembangan kuncup bunga hasil induksi sampai mekar (antesis) memerlukan waktu 19-20 hari, sama dengan bunga yang muncul secara alami. Kuncup bunga hasil induksi yang bertahan sampai bunga mekar sekitar 39,5\% (45 watt) dan 75,7\% (55 watt), akan tetapi hampir semua bunga yang mekar berkembang menjadi buah.

Dalam kajian fisiologi tumbuhan pemberian penyinaran pada budidaya tumbuhan agar tanaman dapat berbuah untuk meningkatkan hasil berkaitan dengan induksi pembungaan. Dugaan Luder dan McMahon (2006) tanaman buah naga (Hylocereus spp.) merupakan long day plants (LDP) / tanaman hari panjang, sehingga induksi pembungaan terjadi pada saat hari panjang. Hal ini terkait dengan fotoperiode. Fotoperiode merupakan fenomena pada berbagai jenis tumbuhan saat panjang hari menentukan apakah meristem pucuk/lateral mampu membentuk bunga atau tidak. Menurut Stirling et al.(2002) fotoperiodisme merupakan tanggapan dari tumbuhan terhadap fotoperiode.

Menurut Sugito (1994) panjang hari (fotoperiodisitas) merupakan lamanya siang hari mulai matahari terbit hingga matahari terbenam. Lebih lanjut Sutoyo (2011) menjelaskan bahwa panjang hari berpengaruh terhadap jumlah cadangan makanan yang dihasilkan tanaman serta menentuan waktu pembungaan. Proses pembungaan dipengaruhi oleh fotoperiode, fitokrom, dan jam biologi. Fitokrom merupakan pigmen yang berperan dalam siklus pertumbuhan dan perkembangan tanaman (Stirling et al., 2002).

Menurut Salisbury dan Ross (1999) tanaman hari panjang (LDP) akan berbunga jika mengalami fotoperiode yang lebih tinggi daripada fotoperiode/ panjang hari kritisnya. Panjang hari kritis adaah panjang hari maksimum pada tanaman hari pendek dan minimum pada tanaman hari panjang saat inisiasi pembungaan masih terjadi. Dengan demikian dapat dijelaskan bahwa buah naga sebagai tanaman LDP jika mendapat lama penyinaran yang lebih panjang, akan memacu pembungaan. Tanaman LDP merupakan tanaman malam pendek, artinya akan berbunga apabila periode kegelapan terus menerus diperpendek dengan pemberian cahaya. Respon tumbuhan terhadap induksi fotoperioda tergantung pada jenis 
tumbuhannya. Hal ini selaras dengan hasil penelitian Palupi dan Farida (2013) yang menyatakan bahwa tanaman buah naga yang tidak diberi penambahan penyinaran tidak membentuk kuncup bunga sama sekali. Sehingga disimpulkan bahwa Hylocereus undatus merupakan tanaman yang sensitif terhadap perlakuan penambahan penyinaran, yang selaras dengan yang dikemukakan Luder dan McMahon (2006) tentang dugaan Hylocereus spp. merupakan tanaman hari panjang yang sensitif terhadap penambahan cahaya.

Kebutuhan panjang hari juga berperan untuk berfotosintesis. Fotosintesis diperlukan untuk menghasilkan pembungaan tanaman. Tanaman buah naga termasuk dalam jenis tanaman CAM (crassulacean acid metabolism). Pada malam hari stomata tumbuhan CAM terbuka di malam hari dan akan tertutup di siang hari. Pemberian penerangan menggunakan bola lampu pada malam hari menyebabkan pembukaan stomata semakin optimal. Dengan demikian laju pengambilan $\mathrm{CO}_{2}$ juga meningkat. Selain itu Menurut Palupi dan Farida (2013) penambahan penyinaran dapat berfungsi sebagai penambahan periode fotosintesis. Dengan demikian asimilat yang dihasilkan akan meningkat. Akumulasi asimilat yang memadai akan memungkinkan terjadinya inisiasi primordia bunga pada bagian meristem.

Pengaruh positif dari cahaya terhadap pembukaan stomata bisa disebabkan karena peningkatan fotosintesis sel penjaga atau karna respon khusus dr sel penjaga terhadap cahaya biru. Terjadinya fotosintesis sel penjaga karna cahaya menyebabkan terjadinya pemompaan aktif ion $\mathrm{K}+\&$ asam malat ke dalam sel penjaga sehingga potensial osmotik sel penjaga menurun air masuk ke dalam sel penjaga. Pemberian cahaya biru juga mengaktifkan pemompaan ion $\mathrm{K}+\mathrm{ke}$ dalam sel penjaga.

\section{SIMPULAN}

Tanaman buah naga sebagai tanaman LDP jika mendapat lama penyinaran yang lebih panjang, akan memacu pembungaan. Tanaman buah naga termasuk dalam jenis tanaman CAM (crassulacean acid metabolism). Pemberian penerangan menggunakan bola lampu pada malam hari menyebabkan pembukaan stomata semakin optimal. Dengan demikian laju pengambilan $\mathrm{CO}_{2}$ sebagai sumber fotosintesis juga meningkat. Penambahan penyinaran dapat berfungsi sebagai penambahan periode fotosintesis. Dengan demikian asimilat yang dihasilkan akan meningkat. Akumulasi asimilat yang memadai akan memungkinkan terjadinya inisiasi primordia bunga pada bagian meristem.

\section{REFERENSI}


Danang, N. 2018. Penelitian Perlakuan Penyinaran Lampu Terhadap Tanaman Buah Naga Bersama Kelompok Tani Binaan CSR PT Bumi Suksesind https://www.linkedin.com/pulse/penelitian-perlakuan-penyinaran-lampu-terhadaptanaman-nugraha-dadang, diakses 10 Agustus 2019.

Firdaus, H., Indriani, Catur, dsn Wahyudi, N.R.C.T. 2019. Powering Dragon Fruit Sukses Berkebun Buah Naga Dengan Teknik Penyinaran Listrik Di Kabupaten Banyuwangi. Seminar Nasional Inovasi dan Aplikasi Teknologi di Industri 2019. 2 Februari 2019.

Hidayah, E., Fatma, G.A., Badriyah,L., dan Hariadi, Y.C. 2016. Optimalisasi Durasi Lama Pencahayaan dengan Menggunakan Lampu Bohlam Pada Budidaya Buah Naga Dalam Kondisi Off-Season. Makalah disajikan dalam Seminar Nasional Jurusan Fisika UM 2016, Universitas Negeri Malang.

Jiang, Liau, Lin, dan Lee. 2012. The photoperiod-regulated bud formation of red Pitaya (Hylocereus sp.). Hort. Science. Vol. 47(8): 1063-1067.

Luders L, McMahon G, 2006. The pitaya or dragon fruit (Hylocereus undatus). Agnote .No: D42. Northern Territory Government 238:10.

Palupi, E.R dan Farida, S. 2013. Induksi Pembungaan Hylocereus undatus di Luar Musim dengan Penyinaran. Prosiding Seminar Nasional Buah Tropika Nusantara II Bukit Tinggi, 23-25 September 2014.

Reindeers, G. 2010. Dragon Fruits. Artikel. Australia: Sub-Tropical Fruit Club of Qld newsletter.

Salisbury,F.B and C.W.Ross. 1999. Plant Physiology. California: Wadworth Publishing.Co.

Stirling, K.J., Clark, R.J, Brown,P.H., and Wilson, S.J. 2002. Effect of Photoperiod on Flower Bud Initiation and Development In Myoga (Zingiber Mioga Roscoe). Scientia Horticulturae. Vol. 95. Issue 3. Pages 261-268.

Sugito, Y.1994. Ekologi Tanaman. Fakultas Pertanian. Universitas Brawijaya Malang.

Tran, D.H., Yen, C.R. dan Chen, Y.K.H. 2015. Flowerig Response of a Red Pitaya Germplasm Collection to Lighting Addition. International Journal of Biological, Biomolecular, Agricutural,Food and Biotechnological Engineering. Vol. 9 (2). 